$$
\begin{aligned}
& \text { RECEIVEO } \\
& \text { NoV } 121998 \\
& \text { OAI }
\end{aligned}
$$

\title{
Technical Support Section Annual Work Plan for FY 1999
}

OAK RIDGE NATIONAL LABORATORY

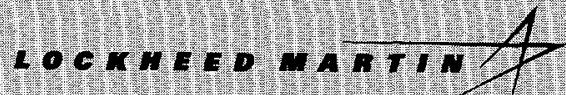
).

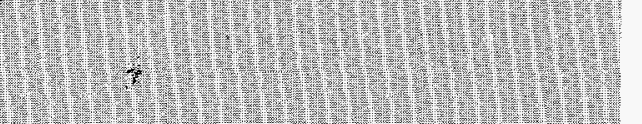

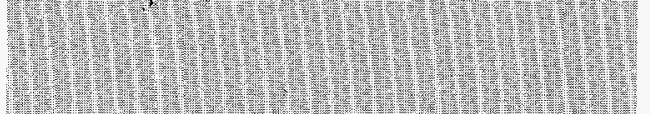
1.1. 1.1. 1.14)

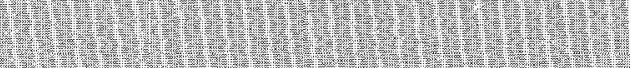
(1) (1) Miti

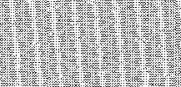

B. P. Adkisson

K. L. Allison

M. E. Boren

B. C. Davis

R. P. Effler

H. C. Ford

R. A. Hess

G. D. Inman

T. A. Keeble

S. M. Odom

J. E. Payne

D. R. Smelcer

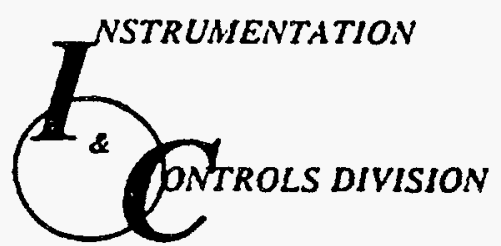


This report has been reproduced directly from the best available copy.

Available to DOE and DOE contractors from the Office of Scientific and Technical Information, P.O. Box 62, Oak Ridge, TN 37831; prices available from (615) 576-8401.

Available to the public from the National Technical Information Service, U.S. Department of Commerce, 5285 Port Royal Rd., Springfield, VA 22161.

This report was prepared as an account of work sponsored by an agency of the United States Government. Neither the United States nor any agency thereof, nor any of their employees, makes any warranty, express or implied, or assumes any legal liability or responsibility for the accuracy, completeness, or usefulness of any information, apparatus, product, or process disclosed, or represents that its use would not infringe privately owned rights. Reference herein to any specific commercial product, process, or service by trade name, trademark, manufacturer, or otherwise, does not necessarily constitute or imply its endorsement, recommendation, or favoring by the United States Government or any agency thereof. The views and opinions of authors expressed herein do not necessarily state or reflect those of the United States Government or any agency thereof. 


\section{DISCLAIMER}

Portions of this document may be illegible in electronic image products. Images are produced from the best available original document. 
Instrumentation and Controls Division

TECHNICAL SUPPORT SECTION ANNUAL WORK PLAN FOR FY 1999
B. P. Adkisson
K. L. Allison
M. E. Boren
B. C. Davis
R. P. Effler
H. C. Ford
G. D. Inman
R. A. Hess
T. A. Keeble
S. M. Odom
J. E. Payne
D. R. Smelcer

Date Published: October 1998

Prepared by

OAK RIDGE NATIONAL LABORATORY

Oak Ridge, Tennessee 37831-6285

managed by

LOCKHEED MARTIN ENERGY RESEARCH CORP.

for the

U.S. DEPARTMENT OF ENERGY

under contract DE-AC05-96OR22464 


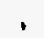

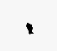




\section{CONTENTS}

Page

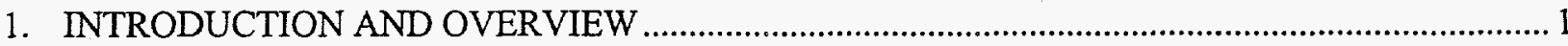

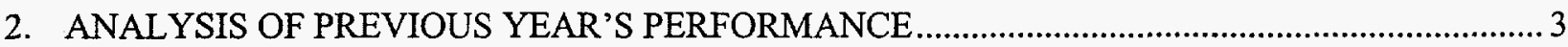

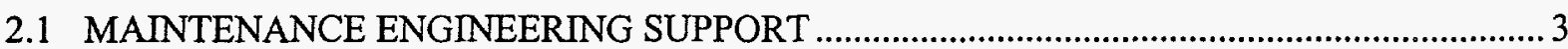

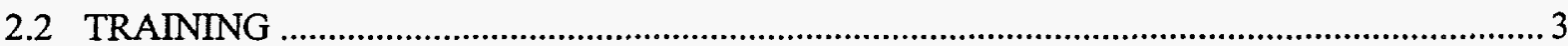

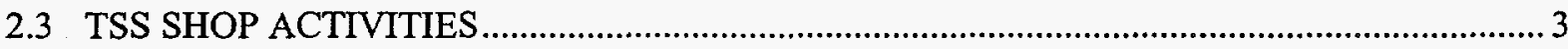

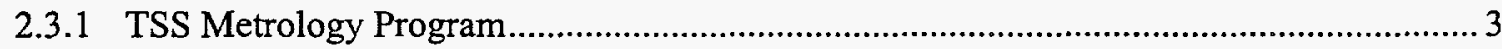

2.3.2 Technical Assistance for a Congressional Demo ......................................................... 4

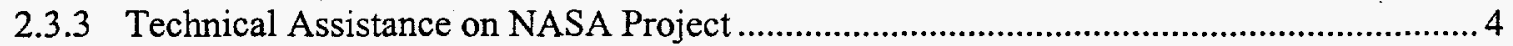

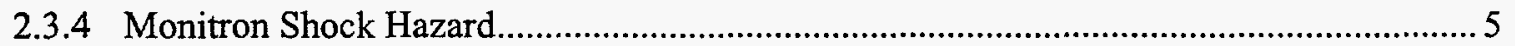

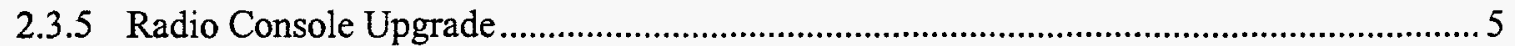

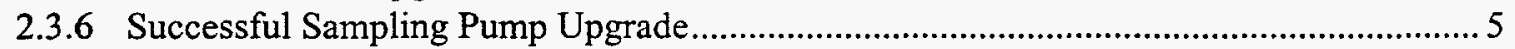

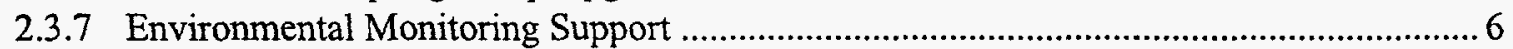

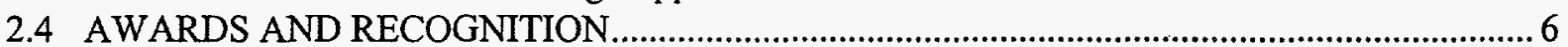

2.4.1 ORNL Award of Excellence in Operations and Support ............................................. 6

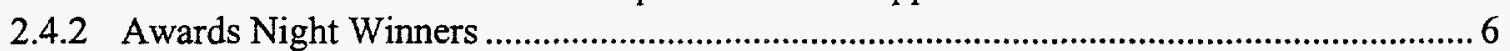

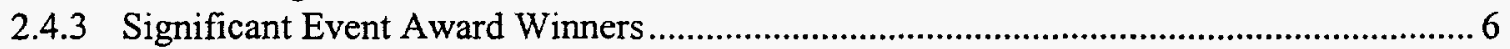

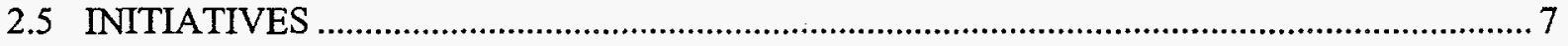

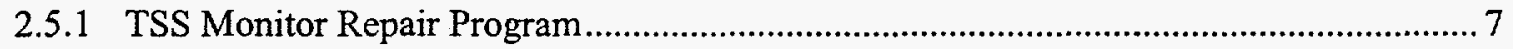

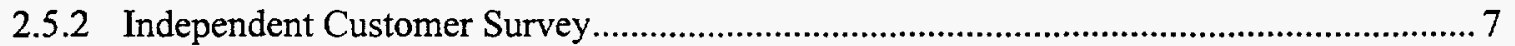

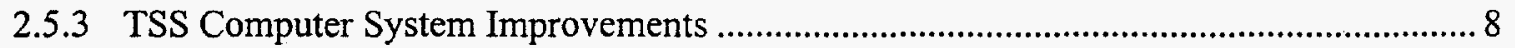

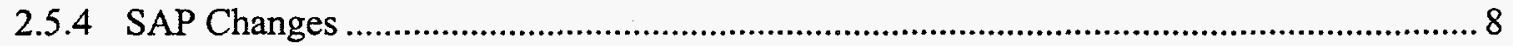

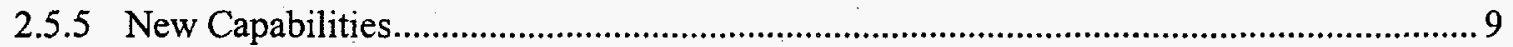

2.6 LEADERSHIP DEVELOPMENT FOR FIRST-LINE SUPERVISORS .................................9

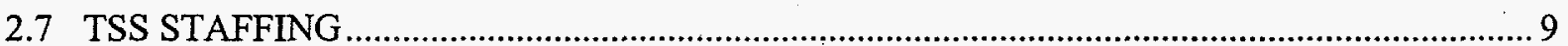

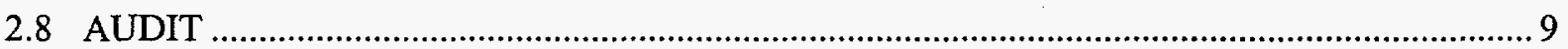

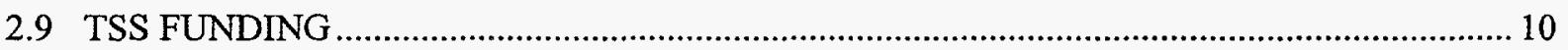

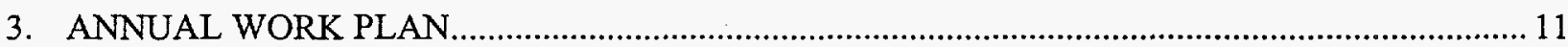

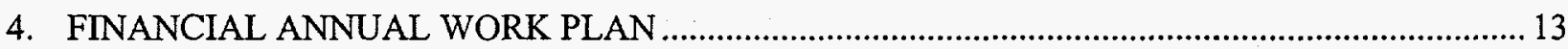

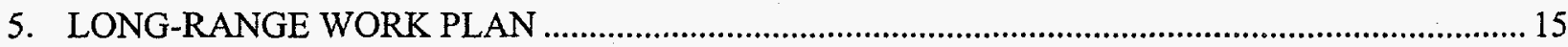





\section{INTRODUCTION AND OVERVIEW}

The Technical Support Section (TSS) of the Instrumentation and Controls (I\&C) Division of Oak Ridge National Laboratory (ORNL) provides technical services such as fabrication, modification, installation, calibration, operation, repair, and preventive maintenance of instruments and other related equipment. It is the mission of TSS to support programs and policies of ORNL, emphasizing safety and ensuring cost-effective support for research and development (R\&D). Work performed by TSS supports basic and applied R\&D, engineering, and instrument and computer systems managed by ORNL.

Because the activities and priorities of TSS must be adapted to the technical support needs of ORNL, the TSS Annual Work Plan is derived from, and is driven directly by, current trends in the budgets and activities of each ORNL division for which TSS provides support. Trends that will affect TSS planning during this period are reductions in the staffing levels of some R\&D programs because of attrition or budget cuts. The new Bechtel Jacobs Company LLC contract for waste management operations at ORNL has added a lot of uncertainty to the overall workload for TSS in the upcoming year. The continued separation between Lockheed Martin Energy Systems (LMES) and Lockheed Martin Energy Research (LMER) also adds to the uncertainty of the TSS workload.

TSS does not have an annual budget to cover operating expenses incurred in providing instrument maintenance support to ORNL. Each year, TSS collects information concerning the projected funding levels of programs and facilities it supports. TSS workforce and resource projections are based on the information obtained and are weighted depending on the percentage of support provided to that division or program. Each year, TSS sets the standard hourly charge rate for the following fiscal year. The standard rate is based on the projected annual inflation rate, proposed increases or decreases in staffing because of perceived changes in program or division funding, upgrade of aging equipment or facilities, overhead burden, compliance with new requirements or directives, labor contract negotiations, and the fringe-benefit rate. The standard rate is charged to customer accounts or work orders as the work is performed. A cost variance occurs when there is a difference between the actual cost per hour and the standard rate per hour. Typically, this variance is positive during months of high fringe-benefit cost (holidays and vacation) or when materials or equipment are costed by Accounts Payable. Variances are negative during months with minimal fringe-benefit cost and when materials purchased for maintenance support are charged back to customer accounts.

The Long-Range Work Plan (see Sect. 5) is based on estimates of the effects of the long-range priorities and directions of the Laboratory. Proposed new facilities and programs provide additional bases for long-range planning. After identification of long-range initiatives, TSS planning includes future training requirements, reevaluation of qualifications for new hires, and identification of essential test equipment that will be needed for new work.

Although TSS has no direct responsibility for the maintenance or repair of real property, it does perform breakdown maintenance, preventive maintenance, and calibration of Laboratory production and experimental equipment, all of which is used for programmatic purposes. Operating expense funds from supported divisions support this type of equipment. 



\section{ANALYSIS OF PREVIOUS YEAR'S PERFORMANCE}

\subsection{MAINTENANCE ENGINEERING SUPPORT}

TSS maintenance engineers/technologists continue to contribute substantially to several projects for ORNL research divisions and for Laboratory support. Evidence of these contributions are the fact that TSS staff have been named as authors on the following ORNL Laboratory Directors Research and Development (LDRD) projects:

A Free-Air $\mathrm{CO}_{2}$ Exposure (FACE) Facility in a Deciduous Forest Experiment Center for Transportation Human Factors Studies

\subsection{TRAINING}

I\&C/TSS Technical Training and Development and Nuclear Facility Qualification programs continue to meet the intent of oversight rules, U.S. Department of Energy (DOE) orders, ORNL directives, and program descriptions. To ensure compliance, training events were conducted, documented, and tracked with state-of-the-art database management and tracking report formats designed by TSS personnel. Developmental training enhanced the overall effort for personnel to remain qualified to perform work in nonreactor nuclear facilities. Hard copy documentation provides an auditable record filed in employee training folders, standardizing formal record keeping. Environmental Safety and Health and Nuclear Facility checklists provide standardized matrices to customize individual training needs. Additionally, employees receive unescorted access training to nuclear facilities based on customer requests and work assignments.

ORNL training providers develop and maintain modules and lesson plans to ensure that personnel remain compliant. On-site technical training provides built-in savings, optimizing time in training with minimum time off the job. By using cost-effective training TSS, is able to reallocate resources for additional employee career development opportunities.

The DOE Handbook on Engineering Symbology, Prints, and Drawings has provided the next level of knowledge for evidence continuing training. TSS subject matter experts observe and document jobrelated instructions for I\&C technicians, technologists, and supervisors by drafting, validating, and ensuring correct performance of technical procedures. In FY 1998, 141 TSS personnel completed 1404 training events, an average of 10 events per person. TSS front-line supervisors receive monthly reports on technician training status and/or deficiencies to effectively manage their assigned cost centers.

\subsection{TSS SHOP ACTIVITIES}

\subsubsection{TSS Metrology Program}

The I\&C Division's Metrology Laboratory, now combined with the TSS calibration program, has significantly changed its focus from pure R\&D to R\&D and facility operations support services. Assets of the old R\&D lab have been consolidated with those of the calibration shops, and the entire 
operation has been reconfigured to improve the work throughput rate. A good deal of surplus equipment was acquired from the old K-25 Metrology Lab and was integrated into the ORNL program; a similar effort is under way to obtain no-longer-needed equipment from the Y-12 metrology organization. A second electronic calibration station has been added by renovating a formerly unused piece of ORNL equipment. To reduce the clerical time required to manage the instrument calibration recall system, an automatically generated e-mail message is now being used to inform instrument custodians that an instrument is due for calibration. This system is more efficient than the erstwhile method of trying to reach each custodian with a telephone call. Further development of this system, which will allow individual jobs in the lab itself to be scheduled automatically, is under way.

A new quality system manual is being developed, and all Metrology Laboratory policies and procedures are being reformatted to conform to ANSI/NCSL Z540, a standard which the DOE Metrology committee recommended for adoption by all DOE metrology organizations.

In addition to supporting ORNL R\&D and facility operations, the I\&C Metrology Lab has also performed a significant amount of work for East Tennessee Technology Park (via a work authorization document) and for Y-12. This is because there are several unique capabilities already in place at the I\&C Metrology Lab, duplication of which at the other plants would not be costeffective.

\subsubsection{Technical Assistance for a Congressional Demo}

Two personal computer/network support technicians were asked to set up the Congressional Demo hosted by ORNL and Dr. Trivelpiece in Washington, D.C. This project was a multilaboratory effort led by Dr. Trivelpiece to demonstrate remote collaboration between all national laboratories and private industry.

With time limitations and restrictions by the House of Representatives, the two technicians were allowed access to the meeting area at 3:00 p.m. In a three-hour period they were required to set up and debug a 12-node local area network (LAN) containing a mix of Sun, PC, and Macintosh computers from sites all around the country. This was done while furniture was being moved, posters were being set up, and caterers were preparing food. Despite all odds, at 6:45 p.m. a fully functional network was in place. Expo participants praised the competence and professionalism of the technicians in performing their work, and Dr. Trivelpiece acknowledged that "despite many technical challenges, the event was an unqualified success."

\subsubsection{Technical Assistance on NASA Project}

Jeff Riggs, an instrument technician working with the Environmental Sciences Division, has traveled across the Ohio-Tennessee River watersheds to install monitoring systems to support a National Aeronautics and Space Administration forest study. The goal of the experiment is to increase understanding of how closed-canopy deciduous forest stands contribute to local and regional hydrologic budgets. We are establishing a distributed set of instrumented forest plots across the watersheds for continuous multiyear monitoring of climate variables, soil and water conditions, and tree and forest stand evapotranspiration. The data from this project will be shared with research groups of the GEWEX Continental-Scale International Project to enhance the databases against which they can test macro- and mesoscale climate models. 


\subsubsection{Monitron Shock Hazard}

An instrument technician was shocked during a routine operational check of a monitron gamma monitor, Model Q5417. A root-cause analysis was implemented with assistance from the Facility Support Group. The investigation team reviewed the incident and provided specific information for analysis of the shock incident. After determining the cause, a course of action was determined and approved by I\&C Engineering, the TSS compliance manager, and the I\&C safety officer. The Facility Support Group drafted a procedure, with review by Engineering, for testing and correction of the hazard, and technicians were trained in the use of the procedure.

The root cause was identified as lack of configuration control as some units had been sent off-site for use at another plant and then returned to ORNL and put into service; these units were identified and checked first. A total of 126 monitrons were identified, located, and tested, and repairs were completed across ORNL. Documentation of the test results and corrective actions were sent to the affected facility managers.

\subsubsection{Radio Console Upgrade}

Radio systems used at ORNL are crucial for effective and timely communications. TSS staff in the Communications and Security Maintenance Shop have been responsible for maintenance of the radio communications consoles at the Laboratory Shift Supervisor's office and the Protective Services Central Alarm Station for many years. Our staff were aware that the consoles had been purchased and installed during the late 1970s and were approaching the end of their useful life. In addition, spare parts were no longer available from the manufacturer because of the age of the equipment. The ORNL radio systems manager and Maintenance Shop staff recommended that the consoles be replaced, but no funds were available to cover the cost of replacement by an outside vendor, which totaled more than $\$ 30,000$.

Shop personnel contacted their counterparts in the Maintenance Department at the Y-12 Plant and discovered that several consoles were being removed as part of the trunking upgrade at the plant. These consoles were newer than the current ORNL consoles and had very little usage on them, making them ideal replacements for the ORNL equipment. After approval was granted for transfer of the equipment, our technicians installed the consoles at ORNL. Y-12 Radio Shop personnel provided technical assistance with reprogramming of the consoles. A total of five consoles were replaced, thus improving radio communications at a fraction of the cost of new equipment.

\subsubsection{Successful Sampling Pump Upgrade}

Technicians of the Electronics Instrumentation Group who support the Chemical and Analytical Sciences Division have been involved with design changes and modifications of air sampling pumps. Initially, 32 pumps were upgraded for the Center for Indoor Air Research. Capacitors were added for memory holding, control board mounting was improved, battery packs were upgraded, and the stop/start switch was modified. The program was successful, and the customer has proposed that we estimate the cost for modifying an additional 60 pumps to be used by the Center for Indoor Research in Korea. The modifications will cost less than $\$ 15.00$ in materials and will require between 3 and 5 hours of technician time for each pump. 


\subsubsection{Environmental Monitoring Support}

TSS process industrial instrumentation technicians replaced 300 voltage direct current (VDC) lithium batteries with ultrastable $300 \mathrm{VDC}$ power supplies in the gross gamma monitors in eight perimeter air monitoring stations throughout the reservation. Instrument technician Mark Klein researched the advantages of replacing batteries with the power supplies. He found that the State of Illinois Department of Nuclear Safety is using power supplies in the same gamma monitors that ORNL uses. They reported details on the reliability and accuracy of the ultrastable power supplies. This modification will result in cost savings because the batteries cost $\$ 300.00$ and have to be replaced annually, but the power supplies cost $\$ 275.00$ each and do not have to be replaced. Moreover, because lithium batteries are hazardous waste, additional cost savings will result from the reduction of hazardous materials requiring disposal.

\subsection{AWARDS AND RECOGNITION}

\subsubsection{ORNL Award of Excellence in Operations and Support}

TSS was awarded the 1998 ORNL Award of Excellence in Operations and Support for outstanding and dependable maintenance of the Laboratory's electronic instruments; for recognized customer service and satisfaction; for dedication to training, quality, and efficiency; and for contributing as integral team members.

\subsubsection{Awards Night Winners}

Two TSS bargaining unit employees and one team of bargaining unit employees received recognition at the annual LMER Awards Night:

- W. C. (Bill) Cochran, for envisioning a better way to accomplish ORNL's mission and persevering to "make it happen" by identifying an untapped resource. He was selected as bargaining unit employee of the year.

- N. R. (Norm) Kurtz, for using his visionary spirit and personal initiative to make ORNL a better laboratory by significantly reducing unnecessary waste.

- T. J. (Tom) Karaus, E. S. (Sue) Bolce, T. E. (Tim) Golden, and T. W. (Tom) Mitchell, for mutual cooperation to establish a valuable new service, which will significantly improve ORNL's ability to accomplish its mission.

\subsubsection{Significant Event Award Winners}

\section{Ed Trowbridge-Facility Support}

TSS engineering technologist Ed Trowbridge received a significant award for his participation in implementing corrective actions for compliance violations of facility authorization basis (FAB) documentation and related implementation of conduct of operations principles. Nine ORNL nonreactor nuclear facilities were involved in the corrective actions. Each facility manager was contacted to review the status of the instrument identified in the FAB documents. Mr. Trowbridge coordinated the activities with the facility supervisors to ensure that the instrumentation would meet the needs of the facility while complying with all operational safety requirements. 


\section{Bill Blodgett-Hazardous Chemical Inventory}

This significant improvement provided a positive correlation between a computer database and the actual physical materials and eliminated the need for the typically crude, barely legible, hand-lettered labels often found on hazardous materials. Mr. Blodgett's foresight and determination to improve the system greatly streamlined the life-cycle tracking of the hazardous materials inventory. This now affords the Building 2033 facility manager the luxury of not having to worry about either incidents or audits and provides a safer workplace for employees in Building 2033, as well as compliance with OSHP-001.

\section{Charlotte Dake-Badge Reader Program}

Charlotte has maintained and operated this entire program. She makes sure that the badge reader units are charged before each meeting, personally oversees the process of scanning badges, and downloads the data and converts it into the format needed for the various target databases. (As any programmer can tell you, this sort of reformatting task alone is an almost miraculous piece of programming sleight of hand.) Charlotte maintains all the programs that process and report these data for the I\&C Division. As if this were not enough, she also takes responsibility for updates of associated internal I\&C and LMER/LMES databases. In case a badged individual from any other organization attends an I\&C-sponsored event, proper notification needs to be made to that individual's division; so Charlotte also ensures that there is a download of LMER/LMES personnel databases to the ICREMS node each week.

\subsection{INITIATIVES}

\subsubsection{TSS Monitor Repair Program}

For years the video display monitors for personal computers have been considered throwaway items-just too hard to repair. Instrument technician Norm Kurtz was not convinced that the monitors could not be repaired. Norm set up a cost-effective, on-site computer monitor repair shop. $\mathrm{He}$ interfaces with vendors and performs warranty service. The average turnaround time for the monitor shop is two days. Norm maintains a stock of loaner monitors to keep customers operating while their monitors are in the shop. He has also set up a Web page to advertise this service. Norm Kurtz has provided ORNL with a better alternative to salvaging monitors-repair them, saving time and money.

\subsubsection{Independent Customer Survey}

From information gathered during the Computer Make/Buy Analysis, a need was identified to do an overall customer survey for all I\&C services. To develop the list of questions, several different appraisal forms used internally at ORNL and some used by private companies were evaluated, and then elements that are important to the way TSS does business were factored into the process. For the survey, division directors were sent letters of introduction and were asked if we could interview members of their staff regarding TSS services. Not all of the divisions responded; however, the ones that did provided several names of people in their organizations to interview. The I\&C quality assurance specialist was given the list of names and a list of questions to ask each person. He conducted the survey, compiled the results, and reported to the I\&C Division director. The report has 
been reviewed, and the I\&C Division director and the TSS head are conducting follow-up meetings with each division to address any questions or issues identified in the survey.

\subsubsection{TSS Computer System Improvements}

The TSS Management Information System, MIDAS/MAJC, has undergone major hardware and software changes. The system was moved from an antiquated VAX 6310 computer to an Alpha System with the latest versions of operating and database software. This move improved the data access speed to as much as 10 times faster. This increase in speed has made data more accessible to end users and has allowed for system database updates to allow more interactive data retrieval programs.

A major on-line improvement was the Job Control System, which allows on-line monitoring of all jobs currently open. These jobs can be assigned to technicians and tracked as they move from start to finish with an up-to-date method of coding the jobs, showing their stages of completion. This has also allowed improvements in on-line querying of the data with as little information as the customer's last name or the equipment ID number. With this enhancement, improved inventory queries were added as well. If users know as little as a portion of the equipment's serial number, within seconds they can locate an instrument in the database of more than 100,000 items.

Another improved area was the recall program. The system was limited to two recall processespreventive maintenance and calibration. This limited some field users from recalling other maintenance functions. The system was improved to allow recall of any activity code that is valid for any given period of time. The end user has the flexibility of defining the beginning recall date or of allowing the system to set it up automatically. Any instrument can be recalled for up to six functions; for example, an item can be operationally checked monthly, preventive maintenance done quarterly, and the calibration done yearly. The recall process allows the item to be set up for frequencies of less than one month (weekly or on 40-day cycles). Each recall process has unique identification of special notations for the job as well as the ability to predefine a customer's current charge number with which to perform recalls.

\subsubsection{SAP Changes}

With implementation of the new LMES/LMER Systems, Applications, and Products in Data Processing (SAP) Management Information System, our maintenance system has had to make many changes. The first of these is the interface of our maintenance job requests (MJRs) with the SAP charging process. The MJR is sent to SAP as an internal order with the associated customer charge number attached. Once it goes into SAP, the MJR is available for material and Payroll, Absence, and Labor System (PALS) charges until it is closed. The MJR details are maintained in SAP and are permanently attached to all charge processes identified to the Internal Order Level. This will greatly improve the traceability of chargeable objects in the business environment as well as supplying the customer with better details of their cost objects over the fiscal year.

Additionally, SAP will be downloading training qualification data, material purchases using the MJRs internal order number, and PALS processes. These data will be put into our system daily and will update our records on-line, greatly improving the quality of tracking our MJRs. 


\subsubsection{New Capabilities}

Recent ORNL internal communications relating the difficulty of finding adequate research funding were not lost on Tom Karaus, Sue Bolce, Tim Golden, and Tom Mitchell, instrument technicians assigned to the I\&C Division's Computer and Network Support Group. On their own initiative, they brain stormed and decided that ORNL had a need for a custom-tailored computer building and upgrade service. Since April 1997, this team has built 144 new computers and upgraded 42 old computers with an average cost savings of $\$ 140.00$ per unit.

\subsection{LEADERSHIP DEVELOPMENT FOR FIRST-LINE SUPERVISORS}

TSS first-line supervisors and Plant and Equipment Division first-line supervisors participated in a workshop for teaming. The workshop was designed to familiarize each group with the working responsibilities of the other group, discuss areas where these responsibilities may overlap, and provide an open forum for discussion. This effort was directed at resolving ongoing grievance issues between the two crafts represented by these supervisors.

\subsection{TSS STAFFING}

Several staffing changes have occurred this reporting period. As a result of transfers and retirements, TSS lost five instrument technicians. Three instrument technicians retired, and two others transferred to the Research Reactors Division.

TSS promoted one instrument technician to engineering technologist and hired a staff engineer from another engineering department in the I\&C Division.

Because of the uncertainty associated with the transition of waste operations activities to the Bechtel Jacobs Company in April 1999, staffing levels in TSS are expected to be somewhat lower than earlier predictions.

\subsection{AUDIT}

The Performance Evaluation Group from LMES conducted a follow-up assessment of ORNL nuclear facilities in July 1998. The assessment revealed significant improvements in operational safety requirement/technical safety requirement (OSR/TSR) compliance compared with the previous visit. The April 1997 assessment results initiated a major revision effort in the FAB documents for each identified nuclear facility. As these documents were approved by DOE and implemented by the facility, the TSS, as a support organization, had to identify the requirement units and revise the facility instrument inventory to meet the requirements.

Meetings were held with each facility manager, and new FAB instrument inventory listings were prepared and signed by both the facility manager and the TSS compliance manager. Instruments were added to or deleted from our inventory and recall process as required, and any new instrument settings were made and documented. Another level of review of instrument data sheets for OSR/TSR designated instruments was added, and this review of maintenance records contributed to the improvement in facility compliance. 


\subsection{TSS FUNDING}

The total TSS budget for FY 1998 was $\$ 9,639,477$, which does not include any overhead funding. This represents an overall charge-out rate of $\$ 50.25$ /hour for the 191,800 hours of service. FY 1998 was a unique year because of the division of the fiscal year into two parts. This division was required because of the changes that occurred in business rules and the flowdown of the cost for space from overhead to the section levels. This resulted in a revised target rate for the year of $\$ 51.36$. TSS operated the year at $\$ 50.25$ /hour for the 191,800 hours of effort provided, which is $\$ 59,768$ less than the revised projected cost. This reduced rate was achieved by analyzing components in the TSS budget, devising ways to reduce spending, increasing productivity, and reductions in staff. The major components of the TSS rate include payroll and fringe (71.7\%), materials $(2.9 \%)$, and support services $(25.4 \%)$.

The FY 1999 rate will be composed of two elements. This includes one element projected to be $\$ 26.14$ for all organizational burden. The second element is projected to be either $\$ 29.22$ or $\$ 33.33$ for wage costs. These amounts differ because of the structure of the wage pools. The majority of all TSS effort will be charged at $\$ 29.22$, and combining this with the organizational burden amounts to $\$ 55.35$ per hour. Components driving the increase include inflation, collection of costs that were previously funded in overhead, and investments TSS is making in the staff through additional training. Additionally, TSS continues to analyze the budget and promote more cost-efficient ways to conduct business. 


\section{ANNUAL WORK PLAN}

TSS used multiple sources of information to determine the projected programmatic level of funding for the next fiscal year. Most divisions projected that their funding levels would remain near those of FY 1998 or slightly decrease. During FY 1998, several reductions in the TSS staff were made through voluntary reduction-in-force incentives. It is projected that these reductions have positioned the section for the appropriate level of staffing for FY 1999.

The redirection of costs from several overhead areas into the TSS budget resulted in an increase in operational costs. Otherwise, FY 1999 operating-expense-funded maintenance and repair requirements for ORNL are projected to be relatively level with those of FY 1998, with increases considered for inflation. Analysis was performed of DOE orders and technical training needs to evaluate training program costs, work force requirements, and types of qualifications for new hires. Routine and breakdown maintenance is expected to remain relatively stable, enabling work to be performed by current staffing levels 
$\bullet$ 


\section{FINANCIAL ANNUAL WORK PLAN}

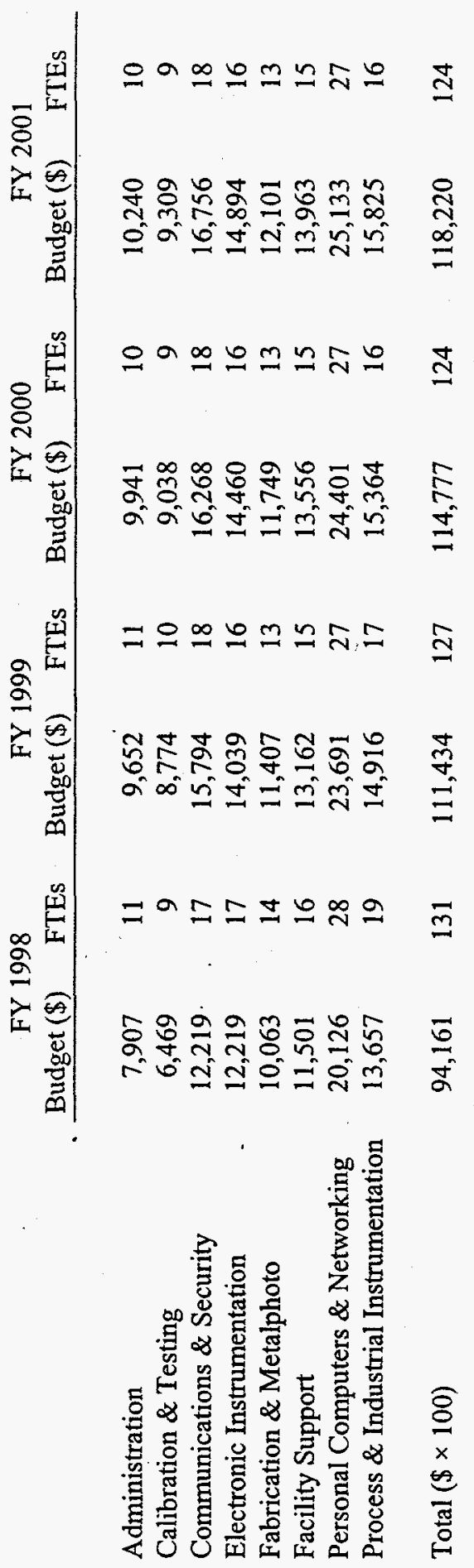




\section{-}

, 


\section{LONG-RANGE WORK PLAN}

Long-range work projections by TSS are based on projections and funding levels of ORNL research divisions. 


\section{-}




\section{INTERNAL DISTRIBUTION}

1. B. P. Adkisson

2. G. T. Alley

3. K. L. Allison

4. M. E. Boren

5. B. C. Davis

6. R. P. Effler

7. H. C. Ford

8. R. G. Gilliland

9. J. L. Hammontree

10-14. R. A. Hess

15. G. D. Inman

16. J. M. Jansen

17. T. A. Keeble

18. D. N. Keller
19. R. C. Mann

20. D. W. McDonald

21. S. M. Odom

22. J. E. Payne

23. D. G. Prater

24. D. R. Smelcer

25. B. K. Swail

26. J. H. Swanks

27. J. D. White

28. Central Research Library

29. Laboratory Records (record copy)

30-31. Laboratory Records (OSTI)

32. I\&C Division Publications Office

\section{EXTERNAL DISTRIBUTION}

33. Edward Cumesty, ORNL Site Manager, DOE-ORO, P.O. Box 2008, 4500N, MS 6269, Oak Ridge, TN 37831-6269

34. Michele G. Branton, ORNL Maintenance Program Manager, DOE-ORO, P.O. Box 2008, 4500N, MS 6269, Oak Ridge, TN 37831-6269

35-39. D. C. Queen, DOE-ORO, P.O. Box 2009, 9114, MS 6269, Oak Ridge, TN 37831-6269

40. Barbara K. McQuiston, YSI, Inc., P.O. Box 279, Yellow Springs, OH 45387

41. Ron Moore, The RM Group, Inc., 12024 Broadwood Drive, Knoxville, TN 37922

42. David Norton, Houston Advanced Research Center, 4800 Research Forest Dr., The Woodlands, TX 77381

43. Gay M. Samuelson, Intel Corp., CH5-148, 5000 W. Chandler Blvd., Chandler, AZ 85226

44. M. M. Sevik, Caderock Division, Naval Surface Warfare Center; Code 70, Bethesda, MD 20084-5000

45. Ernesto Suarez, Pratt \& Whitney, P.O. Box 109600, MS 617-87, W. Palm Beach, FL 334109600 